\title{
The Influences of Urban Building Complexes on the Ambient Flows over the Washington-Reston Region
}

\author{
DA-LIN ZHANG \\ State Key Laboratory of Severe Weather, Chinese Academy of Meteorological Sciences, Beijing, China, \\ and Department of Atmospheric and Oceanic Science, University of Maryland, \\ College Park, College Park, Maryland \\ MENGLIN S. JiN \\ Department of Atmospheric and Oceanic Science, University of Maryland, College Park, College Park, Maryland \\ YIXUAN SHOU \\ Key Laboratory of Radiometric Calibration and Validation for Environmental Satellites, \\ China Meteorological Administration, National Satellite Meteorological Center, Beijing China, \\ and Department of Atmospheric and Oceanic Science, University of Maryland, \\ College Park, College Park, Maryland

\section{CHUNQING DONG} \\ Shanxi Meteorological Observatory, Taiyuan, Shanxi Province, China, and Department of Atmospheric and Oceanic Science, \\ University of Maryland, College Park, College Park, Maryland
}

(Manuscript received and in final form 10 February 2019)

\begin{abstract}
This paper examines the collective impacts of urban building complexes on the planetary boundary layer (PBL) winds using both observations and a mesoscale model. Horizontal winds measured on the rooftops of federal buildings over the regions of Washington, D.C., and a small city nearby (i.e., Reston, Virginia) show the blocking effects of urban building complexes on the downstream winds during the daytime of 9 July 2007. A modeling study of the case using a coupled version of the Weather Research and Forecasting (WRF)multilayer urban canopy model in which the observed building height and density information is implemented to advance the calculations of momentum and heat, reproduces the rooftop-observed wind patterns and the related urban heat island effects, especially the wake flows on the downstream sides of the above-mentioned two cities. Results show that under daytime conditions the building complexes can collectively form a mesoscale wake on the downwind side of each city, about $2-10 \mathrm{~km}$ away, horizontally from the edge of the building complexes. The wake flow may extend to much higher levels than the building tops, depending on the incoming flow strength, the static stability in the PBL, the height of the building complexes, and the time of the day because of the strength of surface insolation.
\end{abstract}

\section{Introduction}

Tall buildings and other large structures in urban areas, ranging from 20 to $200 \mathrm{~m}$ in altitude, not only contribute to the urban heat island (UHI) effects, but also disturb incoming flows in the surface layer and above. The dynamical effects of the obstacles are to modify the incoming flows via drag forming (i.e.,

Corresponding author: Dr. Da-Lin Zhang, dalin@umd.edu pressure differences across buildings) and vertical wake mixing (i.e., turbulent mixing around buildings), thereby modifying the flows downstream, hereafter referred to as the wake flow (Roth 2007). Thus, when an air parcel in the planetary boundary layer (PBL) is advected across a city from the surrounding rural area, it will be slowed down, increasing the vertical wind shear in the PBL while being heated through the UHI effect. Like the wake flows on the lee sides of mountains, a wake flow may appear as a horizontal recirculating flow or vortex 
or vertical turbulent mixing in the wake of an obstacle, depending on the near-surface static stability. The UHI effects associated with urban buildings have been extensively studied for many years in terms of building heating (Manley 1958; Oke 1982; Arnfield 2003; Jin et al. 2005; Rizwan et al. 2008; Zhang et al. 2009, 2011; Jin 2012, 2018). Remarkable work has also been done to analyze building effects on ambient airflows, via most surface observations and building-scale dispersion model simulations over the past few decades (Counihan et al. 1974; Hunt et al. 1978; Meroney 1982; Hanna et al. 2003; Zajic et al. 2011). Both the observational and modeling studies reveal that wake flows occur nearby buildings or large structures as functions of building height, roof structure, static stability, and incoming wind speed.

In addition to the wake flows and vortices nearby obstacles, numerous studies have shown complicated flow and turbulence structures along street canyons (e.g., Nunez and Oke 1977; Nelson et al. 2007; Klein and Clark 2007; Zajic et al. 2011). Klein and Clark (2007) found that the street-canyon flows are highly channeled by the along-canyon component of the above-roof-level flows, implying that small variations in upwind direction could affect the magnitude of the incanyon flows. On an urban scale, the combined dynamical and UHI effects often account for the formation of horizontal convective rolls oriented along the lowlevel mean flow, as a result of increased vertical wind shear and reduced static stability in the PBL (Ackerman 1974; Kropfli and Kohn 1978; Atkinson and Zhang 1996; Miao et al. 2009). By analyzing the urban-scale flow perturbations in the mixing layer from airborne observations, Wong and Dirks (1978) found that UHI effects and urban drag are of relative importance in determining the mixed-layer airflows over the city, depending upon the strength of incoming winds.

While considerable work has been done on the UHI effects and the dynamical building effects inside urban areas, few studies have been performed to examine the collective effects of building complexes on ambient flows and, especially, on the wake flows inside and outside urban areas. In addition, limited research has focused on understanding the collective effects of city sizes and building complexes on the ambient flows outside urban areas. How the urbanization features affect the local and regional-scale winds has received growing interest for aircraft safety, air quality management, convective initiation and heavy rainfall forecasts (e.g., Hicks et al. 2012, 2014; Dou et al. 2015; Li et al. 2017; Liang et al. 2018). The goal of the present study is to provide some fundamental understanding of these issues. To this end, a case study of the impact of building complexes on the generation of wake flows associated with Washington, D.C. (hereafter referred to as DC), and Reston, Virginia, using the coupled Weather Research and Forecasting (WRF) and Noah-multilayer urban canopy model (MUCM) with the building energy parameterization (BEP; Martilli et al. 2002), is conducted, as compared to the coupled WRF-Noah-single-layer urban canopy model (SLUCM; Chen et al. 2011). Note that another large city, that is, Baltimore, Maryland, is not examined herein because of the possible influences of Chesapeake Bay breezes on the generation of wake flows (Zhang et al. 2011).

This study is motivated by the wake flows observed on the downwind sides of DC and Reston, Virginia, on 9 July 2007, through measurements installed on the roofs of federal government buildings over the DC-Reston-Columbia regions by NOAA/Air Resources Laboratory (Hicks et al. 2012, 2014), as will be described in section 3. In this study, we will attempt to address when and how deep the wake flows on the downstream sides of the two cities may occur. Because of the lack of high-resolution threedimensional observations, a numerical modeling case study of the wake flow event of 9 July 2007 using the WRF is performed, following that of Zhang et al. (2009, 2011), but with the MUCM in which building heights over the DC-Reston-Columbia regions are incorporated. Zhang et al. (2011) have examined an extreme UHI event that occurred over the DC-Columbia-Baltimore corridor on 9 July 2007 through a series of ultrahigh-resolution control and sensitivity simulations using a coupled WRF-NoahSLUCM with the National Land Cover Database 2001 (NLCD-2001) land-use data. However, the wake flows mentioned above are not examined because of the use of an early version of the SLUCM (i.e., version 2.2) in which some limited building information is incorporated. In addition, DC $\left(\sim 190 \mathrm{~km}^{2}\right)$ has the population of $\sim 635000$, whereas Reston $\left(\sim 45 \mathrm{~km}^{2}\right)$ is a relatively small and isolated urban area with the population of only $\sim 58000$, based on the 2012 census. Comparing the two inland cities of different sizes with different populations and building heights may shed light on the effects of building density and height on the airflows in the PBL.

The next section summarizes major relevant features of the MUCM and the most recent version of the SLUCM as well as some differences between the two. Section 3 shows the verification of the simulated winds and surface temperature fields against observations taken at the rooftops and some surface stations. Section 4 presents the model-simulated three-dimensional structures 
and evolution of these fields. A summary and concluding remarks are given in the final section.

\section{Model description}

A quadruply nested version 3.6.1 of the WRF Model (Skamarock et al. 2005) is used for this study. The nested domains have $(x, y)$ dimensions of $181 \times 151,244 \times 196$, $280 \times 247$, and $349 \times 349$ with the grid length of $13.5,4.5$, 1.5 , and $0.5 \mathrm{~km}$, respectively, which are the same as those used by Zhang et al. (2011, see Fig. 1 therein). All the domains use 51 layers in the vertical with 27 layers in the lowest $2 \mathrm{~km}$ in order to better resolve the evolution of the urban boundary layer.

The model is initialized at 1200 UTC or 0700 local standard time (LST $=$ UTC -5 h) 7 July 2007 and integrated for $72 \mathrm{~h}$ until 1200 UTC 10 July 2007 . The model initial conditions and its outermost lateral boundary conditions as well as the soil moisture field are taken from the National Centers for Environmental Prediction's (NCEP) $1^{\circ}$-resolution final global analyses. They are also the same as those used by Zhang et al. (2011).

The model physics schemes include 1) a three-class microphysical parameterization (Hong et al. 2004); 2) the Mellor-Yamada-Janjić PBL parameterization (Janjić 1994); 3) the Noah land surface parameterization in which four soil layers and one canopy with 24 land-use categories are incorporated (Chen and Dudhia 2001); and 4) the Kain-Fritsch cumulus scheme (Kain 2004) as an additional procedure to treat convective instability for the first two coarsest resolution domains.

To study the building heights and UHI effects, the WRF-Noah model is coupled with a multilayer urban canopy model with a BEP scheme (i.e., MUCM) in the innermost domain with the finest resolution of $500 \mathrm{~m}$. A sensitivity simulation is conducted in which the most recent version of the SLUCM (Kusaka et al. 2001; Chen and Dudhia 2001) is used in order to examine the relative effectiveness of the MUCM versus the SLUCM in reproducing the observed wake flows over the DCReston regions. To help readers understand the two simulations to be presented in the next section, some details associated with the SLUCM and MUCM are described below.

The SLUCM includes 30-m spatial resolution, three-category urban surfaces (i.e., low-intensity residential, high-intensity residential, and commercial/ industrial/transportation), based on the 2006 U.S. Environmental Protection Agency's NLCD. The dynamic and thermodynamic properties of roofs, walls and roads as well as first-order anthropogenic effects are predefined by specifying roughness length, albedo, emissivity, human-activity-induced heat flux term, and the other surface parameters needed in the surface energy budget. In addition, the National Building Statistics Database (NBSD) at 250-m resolution (Burian et al. 2008) is implemented into the SLUCM in a single layer. Its simplified urban geometry helps simulate the key features including wind profile in the canopy layer, reflection of shortwave radiation, absorption and emission of longwave radiation, shadowing from tall buildings, and heat transfer from road, wall, and roof. Note that the SLUCM used herein is similar to that used in the study of Zhang et al. (2011) except that (i) the NLCD urban surface data are updated to 2006, and (ii) more realistic building height effects are included.

Like in the SLUCM, the MUCM calculates surface temperature, based on the surface energy budget, through solving a prognostic equation that includes urban building height effects by changing roughness length and, consequently, modifying the drag coefficient-the parameters needed for calculating the heat and momentum fluxes. Unlike in the SLUCM, these fluxes are calculated in multiple layers, depending on the heights of buildings. For example, the MUCM with high vertical resolution could resolve the DC downtown area (Fig. 1b) where a few blocks of buildings taller than $50 \mathrm{~m}$ are present, with a large surrounding area of taller than $30-\mathrm{m}$ buildings. For DC (Reston, a small city located at $38.96^{\circ} \mathrm{N}, 77.36^{\circ} \mathrm{W}$ ), the mean and highest building heights represented by the MUCM are 16.2 and $59.0 \mathrm{~m}(5.4$ and $12.7 \mathrm{~m})$, respectively, as compared to 20.4 and $86.6 \mathrm{~m}$ (5.9 and $13.0 \mathrm{~m}$ ) in the original NSBD [National Urban Database and Access Portal Tool (NUDAPT)] data of a $250-\mathrm{m}(1 \mathrm{~km})$ resolution; and the mean building area fraction is $0.18(0.05)$. In addition, the MUCM adds a dispersion term in the turbulent kinetic energy equation and modifies the scale length to include urban building heights for different building areas. The MUCM also includes building trapping solar radiation and remitting longwave radiation from building walls.

The general shape of DC is nearly squared (Figs. 1a,b) and it is surrounded by open farms and Chesapeake Bay on its east, Reston and small mountains with elevation up to $1000 \mathrm{~m}$ to the west, and small towns including Columbia and the city of Baltimore on the north. In July, south-to-southwesterly winds prevail with diurnal variations of bay and land breezes plus some small disturbances induced by local terrain and building complexes. Since the two city areas are less than 30 miles apart from each other (Fig. 1a), there would be little differences in solar radiative forcing as far as surface energy is concerned. 

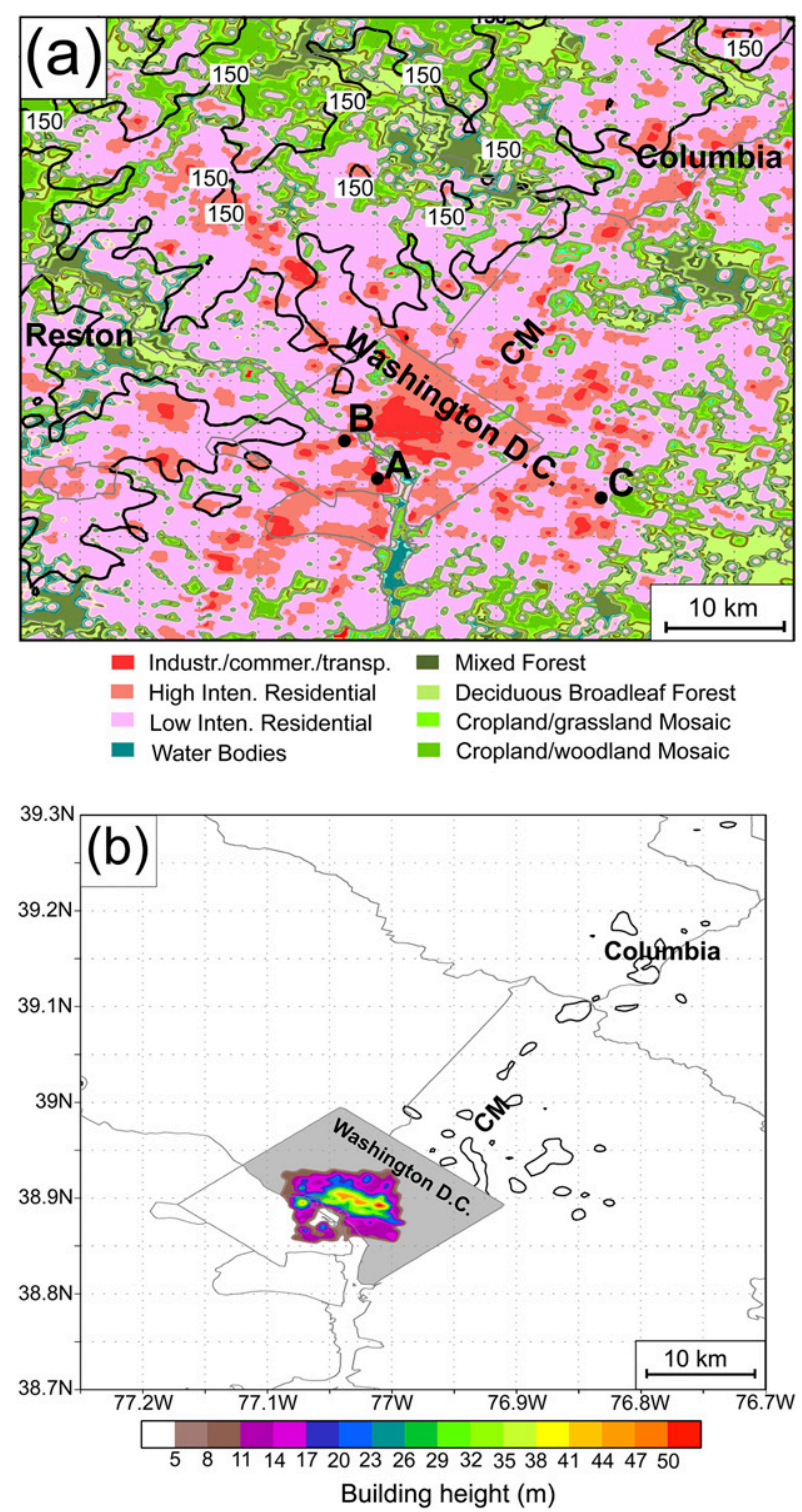

FIG. 1. (a) Dominant land use (shaded) and terrain heights (solid contours, at intervals of $50 \mathrm{~m}$ starting from $100 \mathrm{~m}$ ) over the Washington-Reston-Columbia regions. Letters "A," "B," and "C" denote the respective locations of surface observing stations at the Ronald Reagan National Airport (DCA), the J. Edgar Hoover Building (DC001), and Andrews Air Force Base (ADW) used in Fig. 3. (b) The black rectangle denotes the coverage of building heights, showing the spatial distribution of building heights (m) that are available only in the core area of Washington, D.C. The town of Columbia and its transition with DC, denoted as "CM," are also given.

\section{Observed and simulated urban wind disturbances}

Horizontal winds and air temperatures associated with the urban flows used for the present study are collected through DCnet [see Hicks et al. $(2012,2014)$ for more details], which is a research network of threedimensional sonic anemometer systems erected $10 \mathrm{~m}$ above the rooftops of the federal buildings in DC and its surrounding areas by NOAA/Air Resources Laboratory. The DCNet installations are sited to minimize the possible effects of roof edges and local obstructions. Furthermore, all the observed meteorological data have been averaged over 15-min periods to filter out highfrequency fluctuations (Hicks et al. 2014). Figure 1b shows the distribution of building heights over DC, based on the NBSD, while Fig. 2a plots the building locations providing the observations for the present study. Note that sparsely distributed high buildings over the suburban areas, including the federal buildings of $30-60 \mathrm{~m}$ tall, could not be resolved by the NBSD.

The rooftop-observed horizontal winds and temperatures in the early afternoon of 9 July show clear urban heterogeneities (Fig. 2a). The DC region was dominated by southwesterly winds, even far downstream from DC, with varying wind speeds and directions. Of relevance to this study is that the incoming southwesterly wind turns around as approaching DC, and then clockwise and anticlockwise on the downstream northeast and southwest side of DC, respectively, as circled in red in Fig. 2a. Such symmetric wind-directional turnings are unlikely caused by local factors, given the well-designed DCnet and temporal averaging, as mentioned above. Similarly, in their study of the processes leading to convective initiation in northern Beijing, Li et al. (2017) found that the collective effects of the central urban district of Beijing tend to turn an incoming southerly flow around to an easterly flow on the east-downstream side, accounting for increased convergence in the PBL and the development of an isolated thunderstorm [see Figs. 3 and 5 in $\mathrm{Li}$ et al. (2017)]. Unlike in the present case, such a wind-directional turnaround does not occur on the west-downstream side of Beijing's central urban district because of pronounced topographical forcing to the west. The downstream wind-directional turnaround in both cases resembles wake flows on the lee side of a mountain [e.g., see Fig. 3 in Rotunno et al. (1999)]. A similar feature, albeit at a much smaller extent, appears on the downstream side of Reston, to be more clearly seen later from a model simulation. To our knowledge, this urban-scale wake flow phenomenon has not been well explored in the literature. It should be mentioned that the surface wind perturbations shown in Fig. $2 \mathrm{a}$ are not in the larger-scale flows because a sensitivity experiment conducted by Zhang et al. (2011) in which the Noah land surface scheme is used without incorporating any building height information, shows little evidence of the above flow perturbations [see Fig. 5 in Zhang et al. (2011)]. Thus, we may attribute the generation of the 

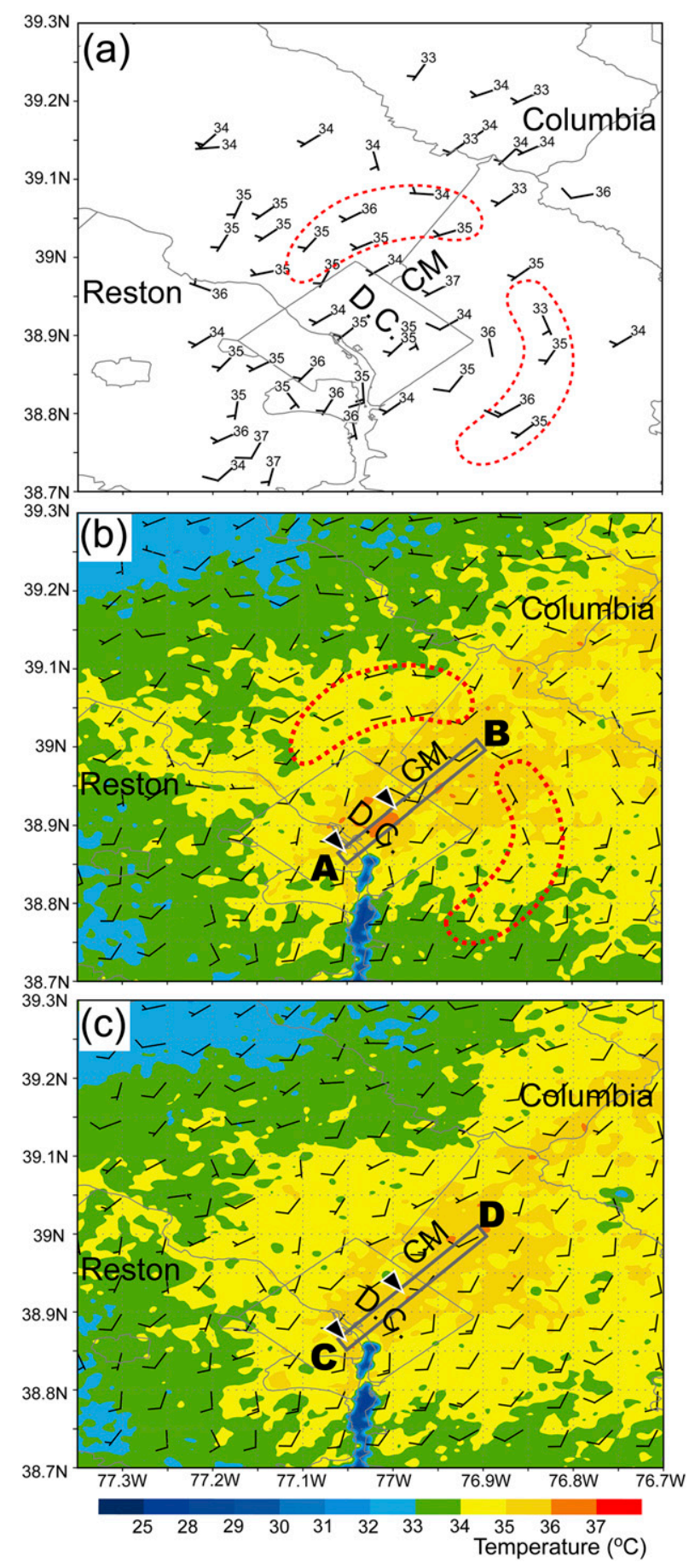

FIG. 2. (a) The rooftop observed horizontal winds $\left(\mathrm{m} \mathrm{s}^{-1}\right)$ and temperatures $\left({ }^{\circ} \mathrm{C}\right)$ at $1245 \mathrm{LST} 9 \mathrm{Jul} 2007$ from the weather instruments installed on the federal building roofs. Dashed circles highlight the areas of wake flows. (b),(c) As in (a), but from the respective MUCM-BEP and the SLUCM simulated horizontal winds at $60 \mathrm{~m}$ above the ground and surface temperature at $2 \mathrm{~m}$ above the ground (color shadings, ${ }^{\circ} \mathrm{C}$ ) at $1245 \mathrm{LST} 9 \mathrm{Jul}$ 2007. Note that a full barb in (a) is $5 \mathrm{~m} \mathrm{~s}^{-1}$, whereas a full barb in (b),(c) is $2.5 \mathrm{~m} \mathrm{~s}^{-1}$. The elongated belts A-B and C-D in (b),(c) will be used to represent the vertical cross sections used in Figs. 5a and 5b, wake winds to the collective impact of building complexes in the cities on the incoming flows, as will be further examined in the next section. Given the measurements taken at the building roofs of $30-60 \mathrm{~m}$ tall, however, it still remains uncertain about how deep the wake flows may extend in the vertical, and how far and wide their influences are, because of the lack of adequate three-dimensional observations at the urban scale. In this regard, we invoke the use of a numerical model to examine the formation and three-dimensional structures of the urban-induced wake flows.

The roof-observed temperatures are also plotted in Fig. 2a, showing that they varied from one building to another (i.e., from $33^{\circ}$ to $37^{\circ} \mathrm{C}$ ), which could be attributed partly to different roof heights, and partly to different thermal and physical properties (e.g., albedo, thermal conductivity, emissivity) of the roofs. Because of the sites locations, these roof-observed temperatures could not be used to explore the UHI effects, which are traditionally studied using paired sites in city and rural regions. Moreover, Zhang et al. (2011) have extensively explored the UHI effects along the WashingtonColumbia-Baltimore corridor. Thus, we will herein focus more on the dynamical impact of building complexes on the ambient flows.

Figure 2b shows the MUCM-simulated horizontal winds at $60-\mathrm{m}$ altitude, which is roughly the mean roof level of federal buildings over the DC region. The simulated surface temperatures are also shown to indicate the distribution of city, suburban and rural regions. It is evident that the model reproduces successfully the wind-directional turning around as approaching DC, and the wake flows, more inward in the highlighted zones and farther northeast than those shown in the measurements. One can even see a couple of wind vectors, occurring at about $15 \mathrm{~km}$ to the northeast of DC's border, that is, near point "B," which point nearly normal to the central axis (i.e., line A-B). The wake flows associated with Reston are also evident, albeit over a very limited area because of its small city size. A comparison between Fig. 2a and Fig. 2b indicates that the simulated weak flows associated with both DC and Reston as well as the simulated general winds over the DC-Reston region compare favorably to the roof observed. That is, the model reproduces higher surface temperatures at the central region of

respectively. Symbol "CM" denotes the transition area from DC's to Columbia's northeastern border; similarly for the rest of figures. Blue triangles in (b),(c) indicate the borders of DC's building complex. 

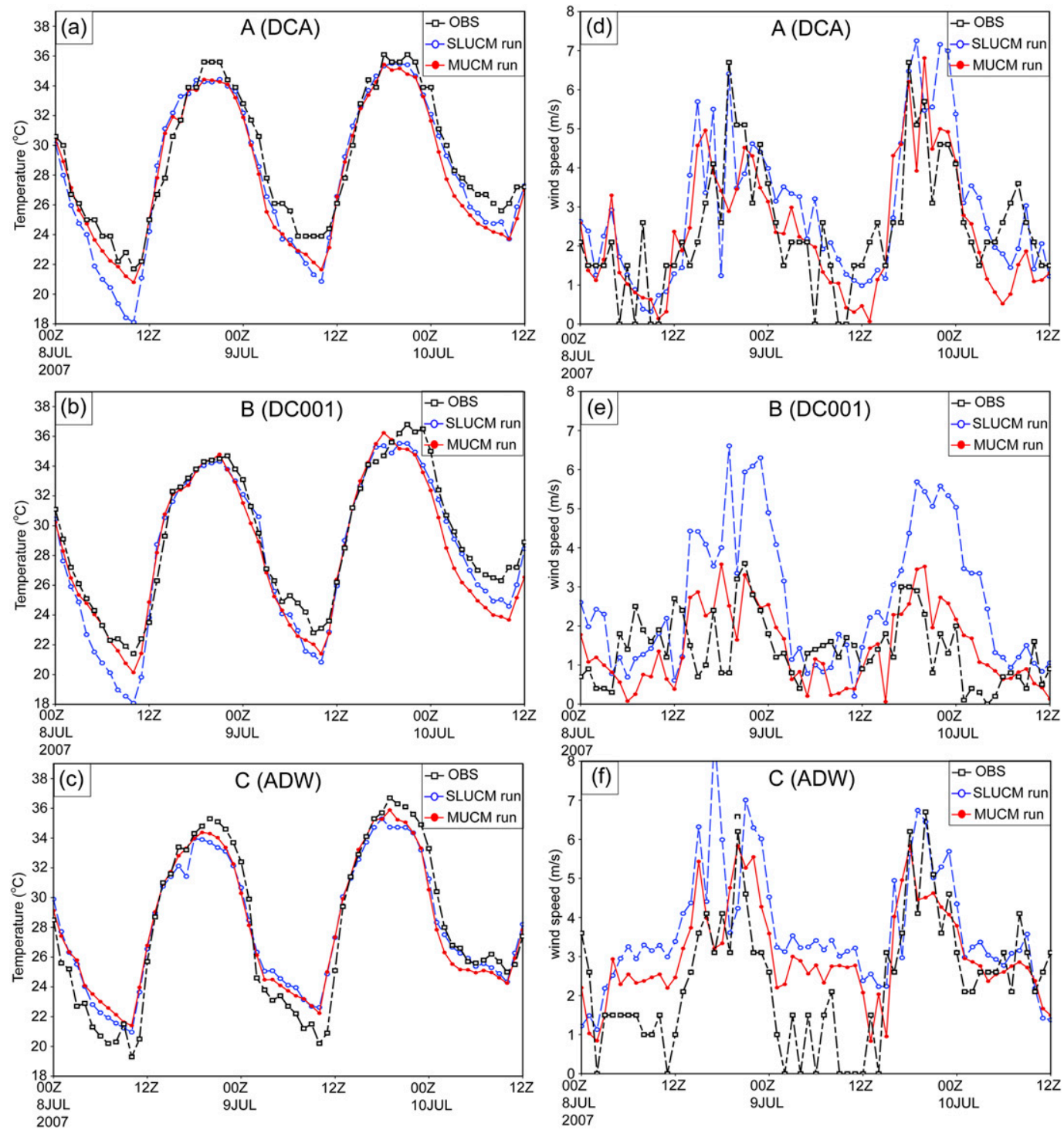

FIG. 3. Comparison of (a)-(c) the MUCM simulated (red) and the SLUCM simulated (blue) surface temperature $\left({ }^{\circ} \mathrm{C}\right)$ to the observed (black) during the period of 1900 LST 7 Jul-0700 LST $10 \mathrm{Jul} 2007$ at points A (DCA), B (DC001), and C (ADW), respectively (see Fig. 1a for their locations), and (d)-(f) as in (a)-(c), but for the surface wind speed $\left(\mathrm{m} \mathrm{s}^{-1}\right)$. The statistics for error analysis are given in Table 1 .

DC, and clockwise and anticlockwise turnings of the incoming flows over the ambient suburban regions. In addition, the roof-level flows in the wake region and farther downstream tend to be weaker than both the incoming flows and the ambient flows, which is also an important feature of wake flows. Based on the model results, we may further confirm that the symmetrically distributed "wake winds" highlighted in Fig. 2a should be attributed to the collective impacts of the urban building complexes upstream (i.e., in DC) rather than to any local forcing, since the MUCM mimics them at nearly the right locations where local buildings are not resolved.
Note that the above wake flows are not evident in the modeling study of the same case by Zhang et al. (2011) because of the use of an early version of the SLUCM. To facilitate the comparison of a single-layer versus a multilayer urban canopy parameterization in reproducing the wake flows, a sensitivity simulation of the SLUCM is performed in which more realistic building effects are incorporated than those used in Zhang et al. (2011), and it is then compared to the MUCM simulation. In particular, whether or not the MUCM simulation performs better than the SLUCM simulation in reproducing the associated wake flows, 
TABLE 1. The root-mean-square error (RMSE) and bias of the simulated surface $(2-\mathrm{m})$ temperature $\left(T_{\mathrm{SFC}},{ }^{\circ} \mathrm{C}\right)$ and the surface $(10-\mathrm{m})$ wind speed $\left(V_{\mathrm{SFC}}, \mathrm{m} \mathrm{s}^{-1}\right)$ from the 12-72-h SLUCM and MUCM runs, respectively, with respect to the corresponding observations at 15 WMO METAR stations over the WashingtonReston-Baltimore regions during 0000 UTC 8 Jul-1200 UTC $10 \mathrm{Jul}$ 2017. The 15 METAR stations are KDCA, KADW, KIAD, KJYO, KDMH, KNAK, KCGS, KGAI, KBWI, KDAA, KHEF, KNYG, and KFDK.

\begin{tabular}{lcccc}
\hline \hline & $\begin{array}{c}T_{\mathrm{SFC}} \\
\mathrm{RMSE}\left({ }^{\circ} \mathrm{C}\right)\end{array}$ & $\begin{array}{c}T_{\mathrm{SFC}} \\
\text { bias }\left({ }^{\circ} \mathrm{C}\right)\end{array}$ & $\begin{array}{c}V_{\mathrm{SFC}} \\
\mathrm{RMSE}\left(\mathrm{m} \mathrm{s}^{-1}\right)\end{array}$ & $\begin{array}{c}V_{\mathrm{SFC}} \\
\text { bias }\left(\mathrm{m} \mathrm{s}^{-1}\right)\end{array}$ \\
\hline MUCM & 1.345 & -0.59 & 1.36 & 0.007 \\
SLUCM & 1.366 & -0.5 & 2.286 & 0.824 \\
\hline
\end{tabular}

UHI effects and the other features need to be addressed.

Thus, the SLUCM-simulated horizontal winds at 60-m altitude and surface temperatures are compared in Figs. 2b and 2c to the MUCM-simulated at 1245 LST 9 July (i.e., near the warmest time). Unlike those shown in Zhang et al. (2011), the SLUCM-simulated wind field could exhibit some evidence of a clockwiseanticlockwise turning couplet on DC's downstream side. However, the directional shifts toward the central axis (i.e., along line A-B) are much smaller than those shown in the MUCM simulation, and there is little evidence of downwind vectors pointing normal to the central axis (i.e., line A-B). This indicates the importance of using multilayers to resolve building heights in reproducing their blocking effects on the ambient flows.

Surface observations available at three stations around DC, as shown in Fig. 1a, are selected to verify the SLUCM- and MUCM-simulated flow fields, respectively (Fig. 3). Two stations (i.e., points $\mathrm{A}$ and $\mathrm{B}$ in Fig. 1a) are located upstream of DC, whereas the third one (i.e., point $\mathrm{C}$ in Fig. 1a) is positioned in one of the highlighted wake flow zones. It is evident from Figs. 3a-c that although both the SLUCM and the MUCM mimic well the diurnal cycles of surface temperatures, the latter does better than the former, especially for two peak values (i.e., the coldest and warmest temperatures), at all the three surface stations. Of importance is that the MUCM reproduces reasonably well the diurnal cycles of surface wind speeds, whereas the SLUCM overestimates them during the daytime, clearly because of the lack of blocking effects (Figs. 3d-f). This overestimation, which will be further seen in the next section, is especially pronounced at points A and B where highelevated buildings are present (Figs. 3e,f). For example, at point A, the MUCM simulation shows a wind speed of $4.2 \mathrm{~m} \mathrm{~s}^{-1}$, which is closer to the observed, whereas the SLUCM has a wind speed as high as $6.6 \mathrm{~m} \mathrm{~s}^{-1}$ (Fig. 3d). Table 1 compares statistical errors of the simulated surface fields from the SLUCM and MUCM runs with respect to those observed at 15 Meteorological Aerodrome Reports (METAR) stations over the DCReston-Baltimore region. It is evident that the rootmean-square errors (RMSE) and biases of the surface temperature obtained from the two runs are comparable in magnitude. Of relevance to this study is that the RMSE and biases of the surface wind speed from the MUCM run are much smaller than those from the SLUCM run. This indicates the importance of incorporating the MUCM into numerical weather prediction models in order to better predict the intensity of surface winds over and in the vicinity of urban regions.

In summary, the coupled MUCM reproduces quite well the observed diurnal cycles of surface temperatures and wind speeds, especially the observed wake flows, over the DC-Reston region during the period of

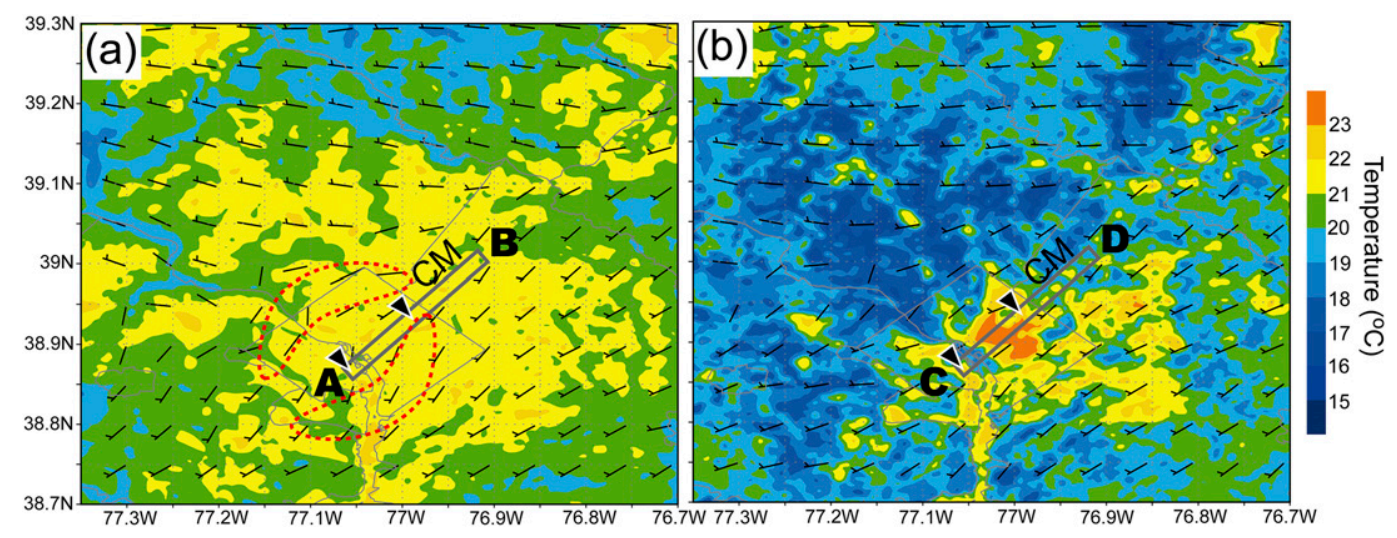

FIG. 4. Comparison of (a) the MUCM-simulated and (b) the SLUCM-simulated horizontal winds ( $\mathrm{m} \mathrm{s}^{-1}$ ) at 30-m height and surface temperatures $\left({ }^{\circ} \mathrm{C}\right)$ around DC at 0500 LST $9 \mathrm{Jul} 2007$ (i.e., the coldest time). The elongated belts A-B and C-D in (a),(b) represent the vertical cross sections with five-slice average used in Figs. 6a and 6b, respectively. A full barb is $2.5 \mathrm{~m} \mathrm{~s}^{-1}$. 
1900 LST 8 July-0700 LST 10 July 2007. This implies that the model output could be utilized in the next section to examine the diurnal and three-dimensional structures of the wake flows. Meanwhile, comparisons of the MUCM run to the SLUCM run can help reveal better the influences of building complexes, resolved in multiple layers, on the ambient flows; meanwhile, they show how well the former simulates the thermodynamical and dynamical impact of urban building complexes.

\section{On the generation of wake flows}

For the reason mentioned above and for the sake of the completeness of the two simulations, comparisons are also made between the MUCM and SLUCM simulations (Figs. 4a,b) at 0500 LST 9 July (i.e., the coldest time), but for horizontal winds at $30-\mathrm{m}$ altitude. As expected, the low-level winds are the weakest at the coldest time because they are decoupled with faster flows aloft under statically stable conditions (Zhang and Zheng 2004). Of significance is that despite the presence of very weak wind speeds (i.e., less than $1.5 \mathrm{~m} \mathrm{~s}^{-1}$ ), the MUCM could also simulate a clockwise-anticlockwise turning couplet associated with the two cities, but with much limited extent of downstream influences; namely, the wake flows occur within and downstream just closer to the cities, as compared to those appearing far downstream from DC's border at the warmest time (cf. Figs. 4a and 2b). (These wind perturbations are much smaller at $60-\mathrm{m}$ altitude, which is why the nocturnal flow fields at $30-\mathrm{m}$ altitude are shown.) This difference in downstream influence extent appears to be attributable to the different wind speeds. That is, the faster wind speeds are the more extensive downstream influences of building complexes. In contrast, the SLUCM-simulated flow field exhibits little evidence of the blocking effects around DC (Fig. 4b).

One may note that the MUCM-simulated surface temperature field differs somewhat from the SLCUCM-simulated at this coldest time (cf. Figs. 4a and $4 \mathrm{~b}$ ). This appears to be attributable to the different ways to estimate the heat fluxes into the ground. Namely, they involve the vertical integration of building surface fluxes from the ground to building roof in the MUCM but a constant heat conductivity of building roofs and walls in the SLUCM (Martilli et al. 2002; Chen et al. 2011). However, such a difference is small during the daytime because of the dominant contributions of sensible and latent heat fluxes in the surface energy budget equation (Zhang and Anthes 1982; Chen and Dudhia 2001).

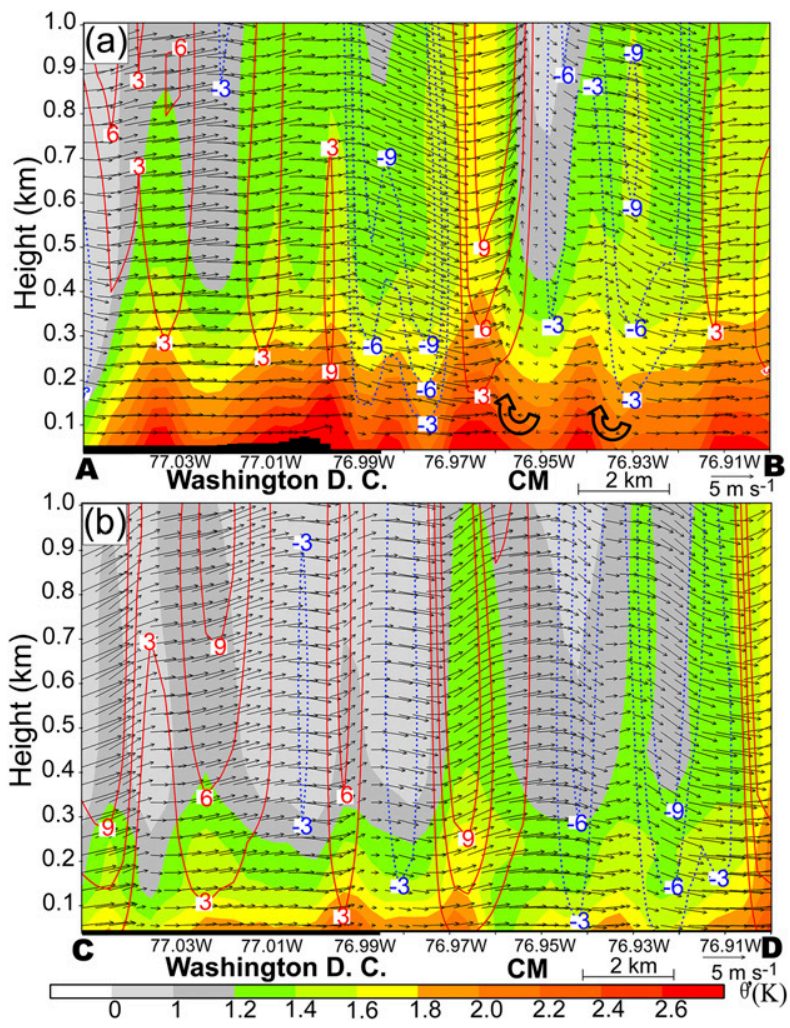

FIG. 5. Vertical cross sections of (a) the MUCM-simulated and (b) the SLUCM-simulated in-plane flow vectors, vertical motion (upward/red-dashed, downward/blue-dashed, every $3 \mathrm{~cm} \mathrm{~s}^{-1}$ ), and potential temperature perturbations (shadings; ${ }^{\circ} \mathrm{C}$; with respect to a vertical profile of the $500 \mathrm{~km} \times 500 \mathrm{~km}$ areaaveraged potential temperature over the region) along an elongated belt A-B, given in Figs. 2b and 2c, at 1300 LST 9 Jul 2007 (i.e., the warmest time). The vertical motion is multiplied by 5 .

Figures 5 and 6 compare the MUCM- and the SLUCM-simulated vertical structures of in-plane flows taken along the mean flow direction through DC at the warmest (i.e., the mixed layer) and coldest (i.e., the most stable) times, respectively. It is evident that both the MUCM and the SLUCM produce warm plumes of increasing depth and intensity from DC's central region to Columbia (and farther downstream) during the daytime mixed-layer development stage, as discussed in Zhang et al. (2011). The SLUCM produces a deep layer of wavelike flows with the strongest vertical motion of about $9 \mathrm{~cm} \mathrm{~s}^{-1}$ across DC and its immediate downstream region at the warmest time (Fig. 5b), which are associated with its UHI effects, and a shallow layer of deceleration of the horizontal flows after passing DC as the wake effect. These features can also be seen from Zhang et al. (2011) but to a much less extent. At the coldest time, Fig. $6 \mathrm{~b}$ shows nearly horizontal motion with little wavy structures 

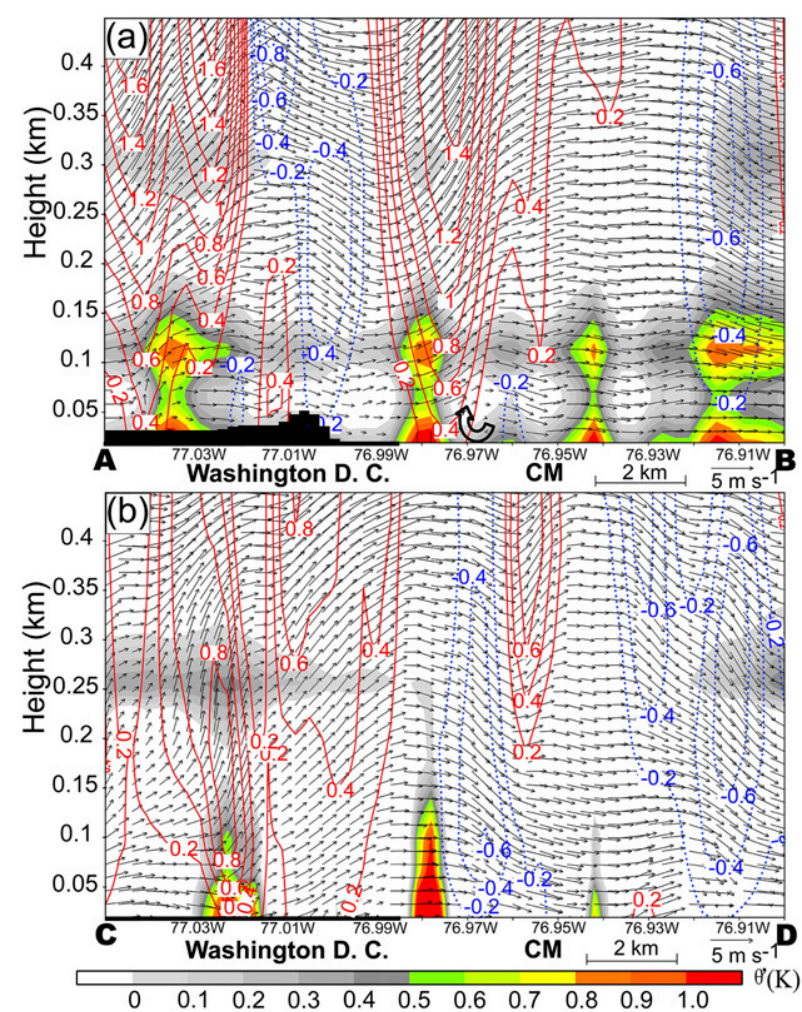

FIG. 6. As in Fig. 5, but along elongated belts A-B and C-D, given in Figs. 4a and 4b, respectively, at 0500 LST 9 Jul 2007 (i.e., the coldest time). Note that the vertical motion is contoured at $0.2 \mathrm{~cm} \mathrm{~s}^{-1}$ intervals, and its vectors are multiplied by a factor of 10 .

(e.g., having the maximum vertical motion of less than $0.8 \mathrm{~cm} \mathrm{~s}^{-1}$ ) across DC, but significant acceleration before reaching CM. The latter phenomenon can be understood as a result of the reduced frictional effects of urbanization.

By comparison, the MUCM simulates a weak in-plane flow region, more significantly in the lowest layers, as entering DC, which is not as evident in the SLUCM run (cf. points A and C in Figs. 5a and 5b, respectively) and is clearly attributable to the blocking effects of building complexes. A vertical column of significant downward motion with pronounced deceleration of horizontal flows in the lowest $300 \mathrm{~m}$ occurs after passing DC, which differs from those produced by the SLUCM. Of particular relevance is the generation of a deep-layer weak flow (and near-stagnated) region with some evidence of reversed flows at $\mathrm{CM}$ in the lowest 300-m layer during the mixed-layer stage (Fig. 5a), since such a stagnation zone has an important implication to the air dispersion problems. Unlike that produced by the SLUCM, the MUCM-simulated wake flows appear on the downstream side of each plume (cf. Figs. 5a and 5b), about $4-8 \mathrm{~km}$. Associated with the lower-level wake flow is the
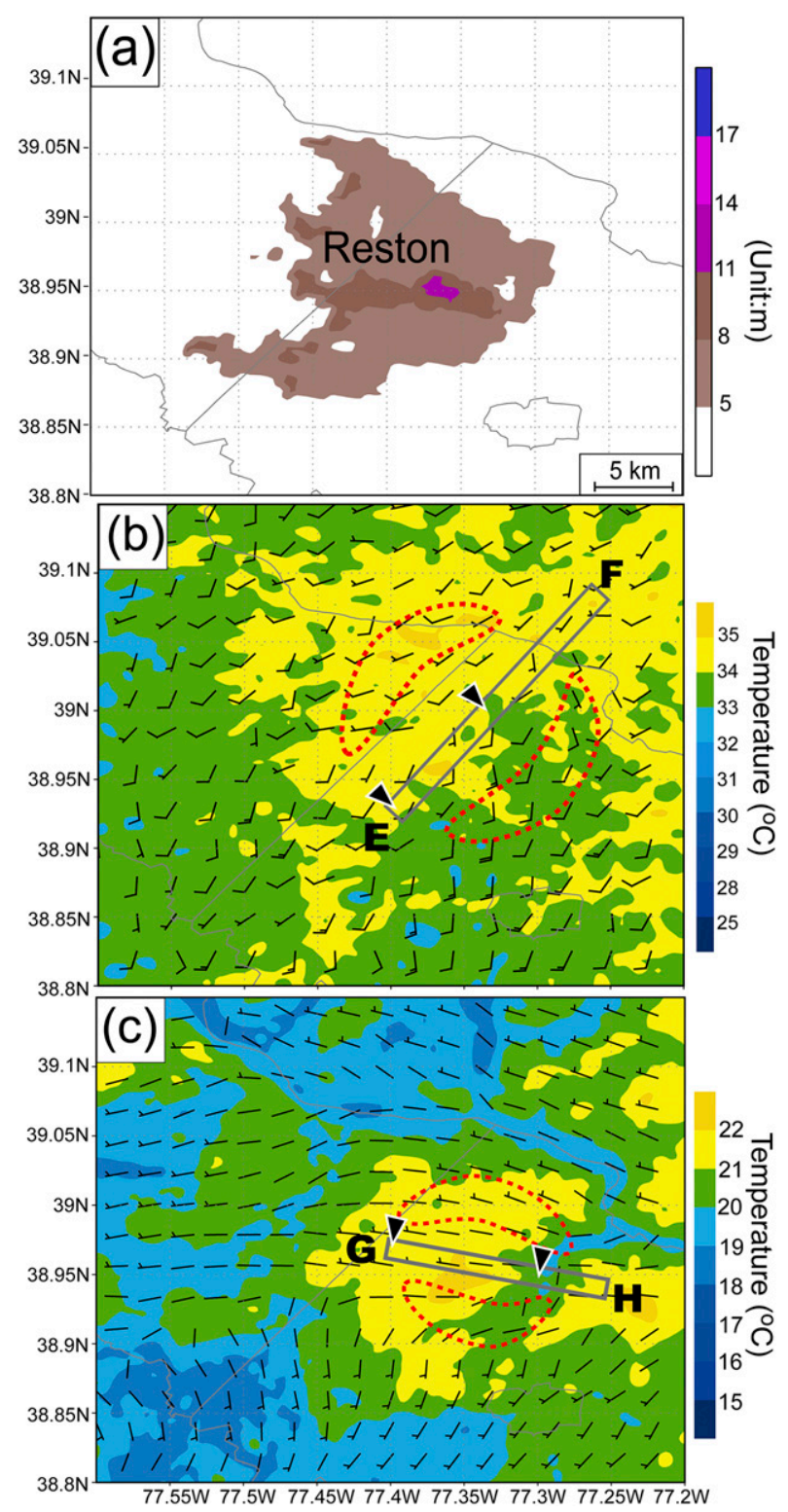

FIG. 7. (a) As in Fig. 1a, but for the dominant land use (shaded) over Reston, Virginia. The MUC-simulated horizontal winds $\left(\mathrm{m} \mathrm{s}^{-1}\right)$ at $60-\mathrm{m}$ height and surface temperatures $\left({ }^{\circ} \mathrm{C}\right)$ at (b) 1300 LST (i.e., the warmest time) and (c) 0500 LST (i.e., the coldest time) $9 \mathrm{Jul}$ 2007. A full barb is $2.5 \mathrm{~m} \mathrm{~s}^{-1}$. The elongated belts $\mathrm{C}-\mathrm{D}$ and $\mathrm{E}-\mathrm{F}$ in (a),(b) represent the vertical cross sections with fiveslice average used in Figs. 8a and 8b, respectively.

presence of pronounced downward wavy structures with vertical wind shear in the vertical, which is similar to that appeared upon approaching DC. Although the blocking effects at the most stable stage are less evident in the vertical (Fig. 6b), partly because of the presence of weak mean flows (i.e., $2 \mathrm{~m} \mathrm{~s}^{-1}$ vs $5 \mathrm{~m} \mathrm{~s}^{-1}$ between the coldest and warmest times in the lowest 1-km layer), the wake flows and associated wave structures can still be clearly 

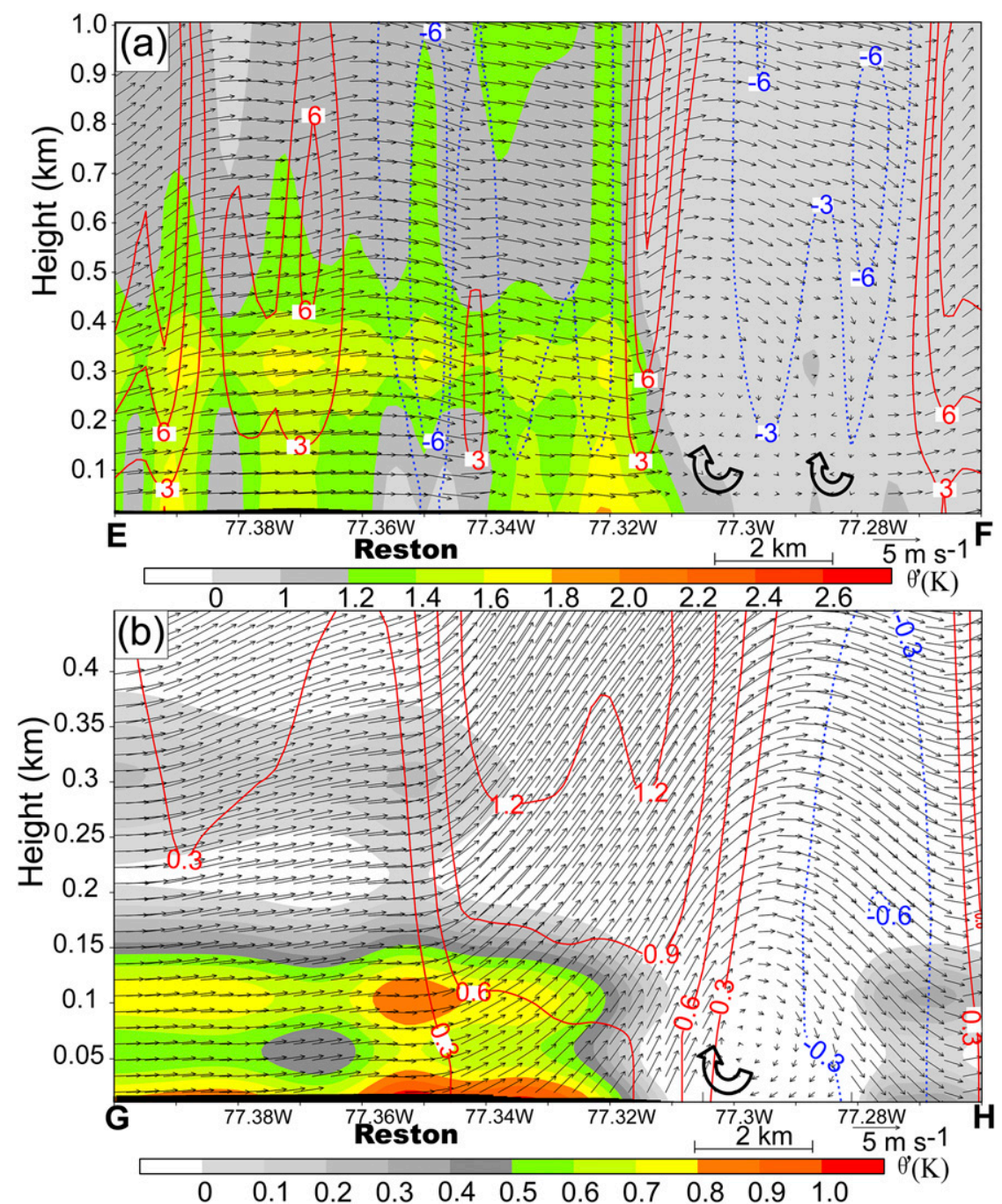

FIG. 8. Vertical cross sections of the MUCM-simulated in-plane flow vectors and vertical motion (dashed, $\mathrm{cm} \mathrm{s}^{-1}$ ) (a) along an elongated belt E-F at 1300 LST (i.e., the warmest time) and (b) along the elongated belt G-H at 0500 LST (i.e., the coldest time) 9 Jul 2007. Note that the vertical motion (upward/red-dashed, downward/blue-dashed) in (a),(b) is multiplied by 5 and 10 , and given at 3 and $0.3 \mathrm{~cm} \mathrm{~s}^{-1}$ intervals, respectively.

seen immediately on the downwind side of DC and $\mathrm{CM}$, albeit in a much shallower layer than that during the mixed-layer stage (cf. Figs. 6a and 5a). The in-plane flows begin to accelerate $2-5 \mathrm{~km}$ downstream away from DC.

The above-mentioned blocking and wake effects occur, more or less, around Reston-an example of small city of about $45 \mathrm{~km}^{2}$ with the highest model building height of less than $13 \mathrm{~m}$ (Fig. 7a). Specifically, the MUCM simulates the reduced southerly and westerly flows as entering the city, and their clockwise and anticlockwise turning around the city, forming the wake flow on the downwind side at the warmest time of 9 July 2007, as highlighted in Fig. 7b. As in the case of DC, more significant blocking and wake effects appear during the mixed-layer stage (Fig. 7c), albeit at a much smaller extent, partly because of the small city size and partly to the absence of influences from some small towns (cf. Figs. 7c, 2b, and 4a). A vertical cross section along the westerly flow branch, given in Fig. $8 \mathrm{~b}$, shows that the blocking and wake effects are limited in the lowest $150-\mathrm{m}$ layer at the most stable stage, with little wavy flows aloft. In contrast, wake flows are evident on the immediate downstream of Reston at the warmest time, like those shown on the downwind side of DC as well as along the building complex (cf. Figs. 8a and 5a). In addition, the wake flows cover a distance of about $5 \mathrm{~km}$ in the lowest 
100-500-m layer and their amplitudes also decrease upward with both altitude and horizontal scale.

\section{Summary and concluding remarks}

This study analyzes the collective effects of urban building complexes on horizontal winds in the PBL through both the rooftop observations of federal buildings over the DC-Columbia-Reston regions and a numerical study using a coupled WRF-MUCM model in which the observed building height and density information is incorporated. The rooftop observations show the generation of wake flows by urban building complexes on the downstream side of the cities, and the coupled WRF-MUCM model reproduces reasonably well the rooftop-observed wake flows and the associated UHI effects as well as the diurnal cycles of surface temperature and winds around DC during the period of 1900 LST 8 July-0700 LST 10 July 2007. An important finding of the present study is that building complexes can form wake flows of different scales on the downstream side of a city with tall buildings. That is, wake flows can form on a building scale (e.g., a few meters from a tall building), individual building complexes (e.g., small towns), and regional scale (e.g., a couple to a few tens of kilometers from a large city or metropolitan region) downwind. Our study shows a regional scale of wake flows induced by urban building complexes, which could be enhanced by the advection of warm air (i.e., the UHI effect) upstream.

Results show that building complexes-induced wakes are functions of building height, speed and direction of incoming horizontal winds, boundary layer stability, and intensity of surface insolation (e.g., time of a day). A deep-layer weak flow region with some evidence of reversed flows or a stagnation zone in the lowest $300-\mathrm{m}$ layer is observed during the daytime mixed-layer stage on the downstream sides of DC and Reston. Wakes can also occur at night, implying that surface insolation is not a necessary condition for wake formation but it may affect it. In other words, urban wakes result mainly from mechanical "blocking," which is modulated by mixed-layer turbulence during daytime. Results also show different downstream locations and vertical extents of wake flows for cities of different sizes and building heights. It is found that the RMSE and biases of the simulated surface wind speed from the MUCM run are much smaller than those from the SLUCM run.

Based on the above results, we may conclude that the thermodynamical and horizontal wind fields in the urban boundary layer and above can be significantly modified by urban buildings of different scales. Our results indicate the importance of incorporating building heights and a multilayer urban canopy scheme into numerical weather prediction models for the studies of urban boundary layer including the UHI effects, urban-scale three-dimensional circulations, and regional weather conditions as well as urban air quality problems. Of course, more high-resolution observational and modeling studies of the impacts of urban-scale building complexes on larger-scale flows over different urban areas should be performed in order to generalize the above conclusions.

Acknowledgments. The authors are grateful to all reviewers for their constructive comments that have helped significantly improve the quality of the manuscript. This work was supported by the FLAGG-MD project of University of Maryland funded by the National Institute of Standards and Technology (NIST) (Grant 2016-NISTMSE-01), and the National Basic Research Program of China (973 Program: 2014CB441402). Thanks go to Dr. Bruce Hicks for providing us with observations on the rooftops of federal buildings along the WashingtonColumbia-Baltimore corridor from DCnet operated by NOAA/Air Resources Laboratory.

\section{REFERENCES}

Ackerman, B., 1974: Wind fields over St. Louis metropolitan area. J. Air Pollut. Control Assoc., 24, 232-236.

Arnfield, A. J., 2003: Two decades of urban climate research: A review of turbulence, exchanges of energy and water, and the urban heat island. Int. J. Climatol., 23, 1-26, https:// doi.org/10.1002/joc.859.

Atkinson, B. W., and J. W. Zhang, 1996: Mesoscale shallow convection in the atmosphere. Rev. Geophys., 34, 403-431, https:// doi.org/10.1029/96RG02623.

Burian, S., N. Augustus, I. Jeyachandran, and M. Brown, 2008: National Building Statistics Database: Version 2. LA-UR-081921, 78 pp.

Chen, F., and J. Dudhia, 2001: Coupling an advanced land surface-hydrology model with the Penn State-NCAR MM5 modeling system. Part I: Model implementation and sensitivity. Mon. Wea. Rev., 129, 569-585, https://doi.org/10.1175/ 1520-0493(2001)129<0569:CAALSH > 2.0.CO;2.

— system: Development, evaluation, and applications to urban environmental problems. Int. J. Climatol., 31, 273-288, https:// doi.org/10.1002/joc. 2158 .

Counihan, J., J. C. R. Hunt, and P. S. Jackson, 1974: Wakes behind two-dimensional surface obstacles in turbulent boundary layers. J. Fluid Mech., 64, 529-563, https://doi.org/10.1017/ S0022112074002539.

Dou, J., Y. Wang, and S. Miao, 2015: Observed spatial characteristics of Beijing urban climate impacts on summer thunderstorms. J. Appl. Meteor. Climatol., 54, 94-105, https://doi.org/ 10.1175/JAMC-D-13-0355.1.

Hanna, S. R., R. Britter, and P. Franzese, 2003: A baseline urban dispersion model evaluated with Salt Lake City and Los Angeles tracer data. Atmos. Environ., 37, 5069-5082, https:// doi.org/10.1016/j.atmosenv.2003.08.014. 
Hicks, B. B., W. J. Callahan, W. R. Pendergrass III, R. J. Dobosy, and E. Novakovskaia, 2012: Urban turbulence in space and in time. J. Appl. Meteor. Climatol., 51, 205-218, https://doi.org/ 10.1175/JAMC-D-11-015.1.

, W. R. Pendergrass III, C. A. Vogel, R. S. Artz, 2014: On the drag and heat of Washington, D.C., and New York City. J. Appl. Meteor. Climatol., 53, 1454-1470, https://doi.org/ 10.1175/JAMC-D-13-0154.1.

Hong, S. Y., J. Dudhia, and S. H. Chen, 2004: A revised approach to ice microphysical processes for the bulk parameterization of clouds and precipitation. Mon. Wea. Rev., 132, 103-120, https://doi.org/10.1175/1520-0493(2004)132<0103:ARATIM> 2.0.CO;2.

Hunt, J. C. R., C. J. Abel, J. A. Peterka, and H. Woo, 1978: Kinematical studies of the flows around free or surface mounted obstacle: Applying topology to flow visualization. J. Fluid Mech., 86, 179-200, https://doi.org/10.1017/S0022112078001068.

Janjić, Z. I., 1994: The step-mountain eta coordinate model: Further development of the convection, viscous sublayer and turbulent closure schemes. Mon. Wea. Rev., 122, 927-945, https://doi.org/10.1175/1520-0493(1994)122<0927:TSMECM> 2.0.CO;2.

Jin, M., 2012: Developing an index to measure urban heat island effect using satellite land skin temperature and land cover observations. J. Climatol., 25, 6193-6201, https://doi.org/ 10.1175/JCLI-D-11-00509.1.

_ 2018: The relationship between surface temperatures and building electricity use: A potential new weather application. J. Build. Sustainability, 1, 28-38.

—, R. E. Dickinson, and D.-L. Zhang, 2005: The footprint of urban areas on global climate as characterized by MODIS. J. Climatol., 18, 1551-1565, https://doi.org/10.1175/JCLI3334.1.

Kain, S. J., 2004: The Kain-Fritsch convective parameterization: An update. J. Appl. Meteor., 43, 170-181, https://doi.org/ 10.1175/1520-0450(2004)043<0170:TKCPAU>2.0.CO;2.

Klein, P., and J. V. Clark, 2007: Flow variability in a North American downtown street canyon. J. Appl. Meteor. Climatol., 46, 851-877, https://doi.org/10.1175/JAM2494.1.

Kropfli, R. A., and N. M. Kohn, 1978: Persistent horizontal rolls in the urban mixed layer as revealed by dual-Doppler radar. J. Appl. Meteor., 17, 669-676, https://doi.org/10.1175/15200450(1978)017<0669:PHRITU>2.0.CO;2.

Kusaka, H., H. Kondo, Y. Kikegawa, and F. Kimura, 2001: A simple single-layer urban canopy model for atmospheric models: Comparison with multi-layer and slab models. Bound.-Layer Meteor., 101, 329-358, https://doi.org/10.1023/ A:1019207923078.

Li, H., X. Cui, and D.-L. Zhang, 2017: Sensitivity of the initiation of an isolated thunderstorm over the Beijing metropolitan region to urbanization, terrain morphology and cold outflows. Quart. J. Roy. Meteor. Soc., 143, 3153-3164, https://doi.org/10.1002/ qj.3169.

Liang, X., and Coauthors, 2018: SURF: Understanding and predicting urban convection and haze. Bull. Amer. Meteor. Soc., 99, 1391-1413, https://doi.org/10.1175/BAMS-D-16-0178.1.

Manley, G., 1958: On the frequency of snowfall in metropolitan England. Quart. J. Roy. Meteor. Soc., 84, 70-72, https://doi.org/ 10.1002/qj.49708435910.

Martilli, A., A. Clappier, and M. W. Rotach, 2002: An urban surfaces exchange parameterization for mesoscale models.
Bound.-Layer Meteor., 104, 261-304, https://doi.org/10.1023/ A:1016099921195.

Meroney, R. N., 1982: Turbulent diffusion near buildings. Engineering Meteorology, E. J. Plate, Ed., Elsevier Scientific, 481-525.

Miao, S., F. Chen, M. A. LeMone, M. Tewari, Q. Li, and Y. Wang, 2009: An observational and modeling study of characteristics of urban heat island and boundary layer structures in Beijing. J. Appl. Meteor. Climatol., 48, 484-501, https://doi.org/ 10.1175/2008JAMC1909.1.

Nelson, M. A., E. R. Pardyjak, J. C. Klewicki, S. U. Pol, and M. J. Brown, 2007: Properties of the wind field within the Oklahoma City Park Avenue street canyon. Part I: Mean flow and turbulence statistics. J. Appl. Meteor. Climatol., 46, 2038-2054 https://doi.org/10.1175/2006JAMC1427.1.

Nunez, M., and T. R. Oke, 1977: The energy balance of an urban canyon. J. Appl. Meteor., 16, 11-19, https://doi.org/10.1175/ 1520-0450(1977)016<0011:TEBOAU>2.0.CO;2.

Oke, T. R., 1982: The energetic basis of the urban heat island. Quart. J. Roy. Meteor. Soc., 108, 1-24, https://doi.org/10.1002/ qj. 49710845502 .

Rizwan, A. M., L. Y. C. Dennis, and C. Liu, 2008: A review on the generation, determination and mitigation of urban heat island. J. Environ. Sci., 20, 120-128, https://doi.org/10.1016/ S1001-0742(08)60019-4.

Roth, M., 2007: Review of atmospheric turbulence over cities Quart. J. Roy. Meteor. Soc., 126, 941-990, https://doi.org/ 10.1002/qj.49712656409.

Rotunno, R., V. Grubišić, and P. K. Smolarkiewicz, 1999: Vorticity and potential vorticity in mountain wakes. J. Atmos. Sci., $\mathbf{5 6}$ 2796-2810, https://doi.org/10.1175/1520-0469(1999)056<2796: VAPVIM $>2.0 . \mathrm{CO} ; 2$.

Skamarock, W. C., J. B. Klemp, J. Dudhia, D. O. Gill, D. M. Barker, W. Wang, and J. G. Powers, 2005: A description of the Advanced Research WRF version 2. NCAR Tech. Note NCAR/TN-468+STR, 88 pp., https://doi.org/10.5065/ D6DZ069T.

Wong, K. K., and R. A. Dirks, 1978: Mesoscale perturbations on airflow in the urban mixing layer. J. Appl. Meteor., 17, 677-688, https://doi.org/10.1175/1520-0450(1978)017<0677: MPOAIT $>2.0 . \mathrm{CO} ; 2$.

Zajic, D., H. J. S. Fernando, R. Calhoun, M. Princevac, M. J. Brown, and E. R. Pardyjak, , 2011: Flow and turbulence in an urban canyon. J. Appl. Meteor. Climatol., 50, 203-223, https:// doi.org/10.1175/2010JAMC2525.1.

Zhang, D.-L., and R. A. Anthes, 1982: A high-resolution model of the planetary boundary layer-Sensitivity tests and comparisons with SESAME-79 data. J. Appl. Meteor., 21, 1594-1609, https://doi.org/10.1175/1520-0450(1982)021<1594:AHRMOT> 2.0.CO;2.

— , and W.-Z. Zheng, 2004: Diurnal cycles of surface winds and temperatures as simulated by five boundary-layer parameterizations. J. Appl. Meteor., 43, 157-169, https://doi.org/ 10.1175/1520-0450(2004)043<0157:DCOSWA > 2.0.CO;2.

_ - Y. Shou, and R. R. Dickerson, 2009: Upstream urbanization exacerbates urban heat island effects. Geophys. Res. Lett., 36, L24401, https://doi.org/10.1029/2009GL041082.

,,--- , and F. Chen, 2011: Impact of upstream urbanization on the urban heat island effects along the WashingtonBaltimore corridor. J. Appl. Meteor. Climatol., 50, 2012-2029, https://doi.org/10.1175/JAMC-D-10-05008.1. 